\section{Influence of Hemostatic Solution on Bond Strength and Physicochemical Properties of Resin Cement}

Isabela Sousa de Araújo', Célio Jesus do Prado' ', Luis Henrique Araújo Raposo', Carlos José Soares², Rayssa Ferreira Zanatta ${ }^{3}$, Carlos Rocha Gomes Torres ${ }^{3}$, Reinaldo Ruggiero ${ }^{4}$, Gisele Rodrigues da Silva ${ }^{2}$

The aim of this study was to evaluate the degree of conversion, color stability, chemical composition, and bond strength of a light-cured resin cement contaminated with three different hemostatic solutions. Specimens were prepared for the control (uncontaminated resin cement) and experimental groups (resin cement contaminated with one of the hemostatic solutions) according to the tests. For degree of conversion, DC $(n=5)$ and color analyses $(n=10)$, specimens ( $3 \mathrm{~mm}$ in diameter and $2 \mathrm{~mm}$ thick) were evaluated by Fourier transform infrared spectroscopy (FTIR) and CIELAB spectrophotometry $\left(L^{*}, a^{*}, b^{*}\right)$, respectively. For elemental chemical analysis $(n=1)$, specimens $(2 \mathrm{~mm}$ thick and $6 \mathrm{~mm}$ in diameter) were evaluated by $x$-ray energy-dispersive spectroscopy (EDS). The bond strengths of the groups were assessed by the microshear test $(n=20)$ in a leucite-reinforced glass ceramic substrate, followed by failure mode analysis by scanning electron microscopy (SEM). The mean values, except for the elemental chemical evaluation and failure mode, were evaluated by ANOVA and Tukey's HSD test. The color stability was influenced by storage time $(p<0.001)$ and interaction between contamination and storage time $(p<0.001)$. Hemostop and Viscostat Clear contamination did not affect the DC, however Viscostat increased the DC. Bond strength of the resin cement to ceramic was negatively affected by the contaminants $(p<0.001)$. Contamination by hemostatic agents affected the bond strength, degree of conversion, and color stability of the light-cured resin cement tested.

\author{
'Department of Occlusion, Fixed \\ Prosthodontics and Dental \\ Materials, School of Dentistry, \\ UFMG - Universidade Federal de \\ Uberlândia, Uberlândia, MG, Brazil \\ ${ }^{2}$ Department of Operative \\ Dentistry and Dental Materials, \\ School of Dentistry, UFMG - \\ Universidade Federal de Uberlândia, \\ Uberlândia, MG, Brazil \\ 3Institute of Science and \\ Technology of São José dos \\ Campos, Restorative Dentistry Area \\ UNESP - Univ Estadual Paulista, \\ São José dos Campos, SP, Brazil \\ ${ }^{4}$ Institute of Chemistry, UFMG - \\ Universidade Federal de Uberlândia, \\ Uberlândia, MG, Brazil
}

Correspondence: Profa. Dra.

Gisele Rodrigues da Silva, Avenida

Pará, 1720, Bloco 4L, Anexo A,

Sala 4LA33, Campus Umuarama, 38405-320 Uberlândia, MG, Brazil. Tel: +55-34-3225-8106. email: giselerosilva@yahoo.com.br

Key Words: bond strength, color analysis, degree of conversion, hemostatic solutions, light-cure resin cement.

\section{Introduction}

The increasing demand for porcelain laminate veneers has led to the continuous development of dental ceramics with improved optical properties, translucency, and esthetics (1). It is well known that restorative ceramic materials require a clinical stage of bonding to tooth structures with adhesive resin cements (2). Thus, the optical behavior of a ceramic restoration is determined by the combination of the color of the underlying tooth structure, the thickness/composition of the ceramic veneer, and the color of the luting cement (3).

The use of light-cured cements is based on the concept that the light emitted by curing units could pass through some indirect restorations, due to their translucency and reduced thickness (1). When bonding is effective, adhesive luting promotes increased fracture resistance of ceramic materials by cement penetration into the irregularities present at the internal surface of the restoration, leading to higher bond strength and lower crack propagation (4) Moreover, photoactivated resin cements (light-cured) have better color stability compared with that of chemically or dual-cured resin cements (5). This fact is probably related to the absence of chemical activator binders (tertiary amines) present in the catalyst, which can cause color changes over time (5).

The degree of conversion (DC), which is the proportion of single carbon-carbon bonds in a polymer matrix to double carbon bonds between monomers (6), implies the conversion of monomers to polymers and is an index for the extent of polymerization. It has been shown that DC can affect the clinical performance of dental composites (6). An inadequate degree of conversion (e.g. low DC) might weaken bonding strengths, lower physicomechanical properties, release toxic materials such as monomers and initiators (7), and cause permeability of bonded interfaces for resin-based materials. Suboptimal polymerization might lead to unfavorable changes, causing restoration detachment, caries formation, or discoloration around the adhesive, all of which are of clinical concern (8).

Usually, indirect restorations, including inlays, onlays, veneers, and crowns, have cervical margins intentionally placed in the gingival sulcus to meet esthetic and functional requirements (9). This leads to subgingival restorations that are often bonded without rubber dam isolation. However, it is well known that contamination by saliva, gingival crevicular fluid, or blood during luting procedures can negatively affect the adhesive properties of resin cements 
(10). To overcome this situation, gingival retraction cords immersed in different hemostatic solutions can be inserted into the gingival sulcus to promote chemomechanical clearance (11).

Chemical solutions used as hemostatic agents, and usually containing aluminum chloride, ferric sulfate, or epinephrine, have the power to control bleeding and gingival flow, allowing practitioners to work in a relatively dry operative field. Aluminum chloride acts on the contraction of blood vessels, inducing the precipitation of mucosal proteins, therefore decreasing capillary fragility. In turn, iron sulfate is a concentrated form of astringent, causing superficial and local coagulation (12). The use of hemostatic agents can be important during luting procedures to avoid blood contamination along the prepared tooth interface and into the luting agent. However, some studies have indicated that hemostatic agents can remain on the tooth surface, causing a significant decrease in bond strength to dentin (13). In addition, previous studies have demonstrated that hemostatic agents are highly acidic, with $\mathrm{pH}$ varying from 0.7 to 3.0. The acidity of these solutions may also contribute to changes in the dentin surface (14).

Thus, the aim of this study was to evaluate the degree of conversion, color stability, chemical composition, and bond strength of a light-cured resin cement contaminated with different hemostatic solutions containing aluminum chloride or ferric sulfate. The null hypothesis tested was that the hemostatic solutions would not alter the chemomechanical, the bonding interaction with ceramic or optical properties of the light-cured resin cement.

\section{Material and Methods}

The materials used in this study are shown in Table 1. The control group (CT) consisted of uncontaminated specimens of the light-cured resin cement (Variolink Veneer,
Shade +1 , Ivoclar Vivadent, Schaan, Liechtenstein). For the experimental groups, the resin cement specimens were contaminated with three different hemostatic solutions, two of them containing aluminum chloride, Viscostat Clear (VC - Ultradent Products Inc., South Jordan, UT, USA) and Hemostop (HS - Dentsply Herpo, Petrópolis, RJ, Brazil), and one containing ferric sulfate, Viscostat (VS - Ultradent Products Inc.).

\section{Specimen Preparation (Degree of Conversion, Color Stability and EDS Analysis)}

The control group specimens were made by insertion of the light-cured resin cement into silicon molds. The material was covered with Mylar strips, followed by photoactivation with a LED curing unit $\left(1000 \mathrm{~mW} / \mathrm{cm}^{2}\right.$, Radii Plus, SDI, Victoria, Australia) for $40 \mathrm{~s}$. For the experimental groups, specimens were made by the mixing of $10 \mathrm{wt} \%$ of one of the hemostatic solutions with $100 \%$ of the resin cement (nearly $5 \mu \mathrm{L}$ of hemostatic solution to $0.0775 \mathrm{~g}$ of cement) for $5 \mathrm{~s}$, according to each experimental group. The contaminated resin cement was then placed into the silicon molds and photoactivated by the same protocol described above.

Cylindrical resin cement specimens $(2 \mathrm{~mm}$ in height and $3 \mathrm{~mm}$ in diameter) were made in silicon molds for evaluation of the degree of conversion $(n=5)$ and color stability $(n=10)$. For $x$-ray energy-dispersive spectroscopy (EDS) analysis, specimens $6 \mathrm{~mm}$ in diameter and $3 \mathrm{~mm}$ in height were produced for each group $(n=1)$.

\section{Degree of Conversion (DC)}

First, a non-photoactivated portion of the resin cement from each group was subjected to initial readings. The cement was inserted into the crystal of a Fourier transform infrared spectrometer unit (Vertex 70, Bruker Co., Ettlingen, Germany). This first reading was considered the control, since it provided the values of the areas corresponding

Table 1. Materials used in the study

\begin{tabular}{|c|c|c|c|}
\hline Material & Name & Composition & Manufacturer \\
\hline $\begin{array}{l}\text { Light-cured } \\
\text { resin cement }\end{array}$ & $\begin{array}{l}\text { Variolink Veneer, } \\
\text { Shade }+1\end{array}$ & $\begin{array}{l}\text { Dimethacrylates, silicon dioxide and ytterbium trifluoride. } \\
\text { Additional contents: catalysts, stabilizers and pigments }\end{array}$ & Ivoclar Vivadent \\
\hline $\begin{array}{l}\text { Leucite-reinforced } \\
\text { glass ceramic }\end{array}$ & $\begin{array}{l}\text { IPS Empress } \\
\text { CAD, Shade LTA1 }\end{array}$ & $\begin{array}{c}\qquad \mathrm{SiO}_{2} \\
\text { Additional contents: } \mathrm{Al}_{2} \mathrm{O}_{3}, \mathrm{~K}_{2} \mathrm{O}, \mathrm{Na}_{2} \mathrm{O} \text {, CaO, and other oxides, pigments }\end{array}$ & Ivoclar Vivadent \\
\hline Bonding agent & Monobond Plus & $\begin{array}{l}\text { Ethanol, 3-trimethoxysilylpropyl methacrylate, } \\
\text { Methacrylated phosphoric acid ester }\end{array}$ & Ivoclar Vivadent \\
\hline Hydrofluoric acid & Condac Porcelana & $\begin{array}{l}\text { Hydrofluoric acid 10\% } \\
\text { Water, thickener, surfactant and dye. }\end{array}$ & FGM \\
\hline \multirow{3}{*}{$\begin{array}{l}\text { Hemostatic } \\
\text { solutions }\end{array}$} & Hemostop & $\begin{array}{l}\text { Aluminum chloride, propylene glycol, } \\
\text { hydroxyquinoline, ethyl alcohol, water }\end{array}$ & Dentsply Herpo \\
\hline & Viscostat & $20 \%$ anion ferric sulphate & Ultradent Products \\
\hline & Viscostat Clear & $25 \%$ aluminum chloride & Ultradent Products \\
\hline
\end{tabular}


to the bands of the aromatic rings and aliphatic double bonds prior to polymerization of the material under study (reading of the monomer). The aliphatic carbon chains $(\mathrm{C}=\mathrm{C})$ corresponded to the intensity of the absorbance peak located at the $1638 \mathrm{~cm}^{-1}$ band of each spectrum, while the $1608 \mathrm{~cm}^{-1}$ band corresponded to the aromatic carbon chain (15). The analysis of the latter band, considered inherent to the material composition, was used as an internal control for calculation of the percentage of carbon double bonds remaining after polymerization (16). In this study, for the calculation of the DC, the absorption peak of the $\mathrm{C}=0$ ester groups ( $1716 \mathrm{~cm}^{-1}$ band) was used as reference, because no aromatic peaks were identified for the resin cement tested. According to Gajewski VE et al., 2012 (17), composites containing urethane should be analyzed with the $\mathrm{C}=0$ bond $\left(1716 \mathrm{~cm}^{-1}\right)$.

The measurement of the $D C$ was then determined following $24 \mathrm{~h}$ of initial curing (photoactivation), performed for all groups. The infrared spectra were obtained in the crystal with the spectrum software (OPUS, version 6.5, Bruker) used in the microcomputer controlling the spectrometer. This software was used with a resolution of $4 \mathrm{~cm}^{-1}$, and the spectra were collected in the range $1665-1580 \mathrm{~cm}^{-1}$.

\section{Color Stability}

For the analysis of color stability, the specimens were ground flat with 320- to 600-grit silicon carbide papers for $30 \mathrm{~s}$, immersed in an ultrasonic bath with deionized water for 10 min (Ultrasonic Cleaner, Odontobras, Ribeirão Preto, $\mathrm{SP}, \mathrm{Brazil)}$, and then stored in artificial saliva. The immersion in artificial saliva aimed to simulate the oral environment and is frequently used in studies of color evaluation as the media for samples hydration and storage (18). The artificial saliva composition was chloramine $0.5 \%$; potassium chloride $20.9 \mathrm{~g}$; sodium chloride $28.8 \mathrm{~g}$; magnesium chloride $1.86 \mathrm{~g}$; calcium chloride $5.54 \mathrm{~g}$; potassium phosphate 10.86

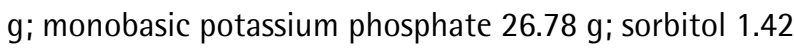
$\mathrm{g}$; sodium benzoate $0.034 \mathrm{~g}$ and distilled water $1000 \mathrm{ml}$.

The color analysis was first carried out $24 \mathrm{~h}$ after specimen preparation, after which the specimens were stored in artificial saliva and analyzed again after 30 days and 6 months of storage. The readings assessed at $24 \mathrm{~h}$ were used as baseline for the analysis of color variation.

The baseline color coordinates were assessed in standard conditions by means of a reflectance spectrophotometer (CM-2600d, Konica Minolta, Osaka, Japan). The device was adjusted for the D65 light source, with 100\% ultraviolet and specular reflection included. The observer angle was set at 2 degrees, and the device was adjusted to a small reading area (SAV), with a total area of $3 \mathrm{~mm}^{2}$. The spectrophotometer was adjusted for three consecutive readings, which were later averaged. The results of the color readings were quantified in terms of the $L^{*}, a^{*}, b^{*}$ coordinate values established by the Commission Internationale de I'Eclairage (CIELAB system), in which the $L^{*}$ axis represents the degree of lightness within a sample and ranges from 0 (black) to 100 (white). The $a^{*}$ plane represents the degree of green/red, and the $b^{*}$ plane represents the degree of blue/ yellow (18). The measurement of color change after aging process was made calculating the variation (delta $-\Delta$ ) of $\mathrm{L}^{*}(\Delta \mathrm{L}), \mathrm{a}^{*}(\Delta \mathrm{a})$, and $\mathrm{b}^{*}(\Delta \mathrm{b})$. The total color change $(\Delta \mathrm{E})$ was calculated according to the following formula (18).

$$
\Delta \mathrm{E}=\left(\Delta \mathrm{L}^{2}+\Delta \mathrm{a}^{2}+\Delta \mathrm{b}^{2}\right)^{1 / 2}
$$

\section{Elemental Chemical Analysis}

A specimen from each group was gold-sputtered (IN SCD050, Leica, Wetzlar, Germany) and subjected to elemental chemical evaluation performed by $\mathrm{x}$-ray energydispersive spectroscopy (EDS/EDX, Oxford Instruments, Abingdon, Oxfordshire, UK) coupled to a scanning electron microscope (EVO MA 10, Carl Zeiss, Jena, Oberkochen, Germany). The equipment performs the analysis based on backscattered electrons, detecting qualitatively and semiquantitatively the constituent chemical elements of the resin cement specimens and the chemical changes that occurred due to contamination with hemostatic agents. All readings were performed $24 \mathrm{~h}$ after specimen preparation.

\section{Microshear Bond Strength Testing ( $\mu S B S$ )}

Forty leucite-reinforced glass ceramic blocks (IPS Empress CAD LT A1, Ivoclar Vivadent) were used as the substrate for $\mu \mathrm{SBS}$ testing, with ten blocks per group. The blocks were embedded with polystyrene resin (Aerojet, Santo Amaro, SP, Brazil) in PVC cylinders, and the ceramic surfaces were ground flat with silicon carbide papers (\#600-, 800-, 1200-grit, Norton, Campinas, SP, Brazil) for $20 \mathrm{~s}$ for surface standardization. The surfaces of the ceramic blocks were then etched with 10\% hydrofluoric acid (Condac Porcelana, FGM, Joinville, PR, Brazil) for $60 \mathrm{~s}$, cleaned with water spray for $1 \mathrm{~min}$, and air-dried with an oil-free jet stream. A silane coupling agent (Monobond $S$, Ivoclar Vivadent) was then actively applied for $20 \mathrm{~s}$ and left to react for an additional $60 \mathrm{~s}$. The light-cured resin cement was then used to fill small molds cut from micro-bore tygon tubing (TYG-030, Small Parts Inc., Miami Lakes, FL, USA), with internal diameter and height of approximately 0.75 and $1 \mathrm{~mm}$, respectively. Six cylinders were placed in the glass-ceramic surface, and a separating space of $3.0 \mathrm{~mm}$ between the cylinders was established, since a safe distance was necessary to prevent unwanted stress from reaching the adhesive interface of the non-loaded cylinders during the test. The cylinders were photoactivated for $40 \mathrm{~s}$ each 
according to the same protocol described previously. The tygon tubing was carefully removed with a scalpel blade, and the specimens were stored in artificial saliva. From the six cylinders placed, two were randomly selected for immediate testing after $24 \mathrm{~h}$. The remaining specimens were stored in artificial saliva and tested following 1 month and 6 months of storage.

For the $\mu \mathrm{SBS}$ test, a metallic jig was coupled to a mechanical testing machine (OM100, Odeme Dental Research, Luzerna, SC, Brazil), and the polystyrene cylinder containing the ceramic block was placed on the device so that the resin cylinder specimens were positioned perpendicular to the looped-orthodontic wire with a diameter of $0.2 \mathrm{~mm}$ ( $\mathrm{NiCr}$, Morelli, Sorocaba, SP, Brazil). This wire was placed around one of the resin cylinders, and the $\mu \mathrm{SBS}$ test was performed by stressing specimens to failure under tension at $0.7 \mathrm{~mm} / \mathrm{min}$. The bond strength of each specimen ( $\mathrm{MPa}$ ) was calculated according to the following formula:

$S=F / A$

where $F$ is the force required to failure $(N)$, and $A$ is the bonded area of the specimens $\left(\mathrm{mm}^{2}\right)$.

\section{Failure Mode}

The fractured surfaces resulting from the $\mu \mathrm{SBS}$ test were cleaned in an ultrasonic bath and gold-sputtered for examination by scanning electron microscopy (EVO MA 10, Carl Zeiss). Failure modes were divided into five types: 1) adhesive failure; 2) mixed failure with prevalence in ceramic; 3) mixed failure with prevalence in resin cement; 4) cohesive failure in ceramic; and 5) cohesive failure in resin cement.

\section{Statistical Analysis}

After being analyzed for normal distribution, data from the color was analyzed by Repeated Measures ANOVA. $\mu$ SBS data were subjected to analysis of 2-Way ANOVA. Regarding degree of conversion, data was submitted to One-way ANOVA. The post hoc Tukey's test was performed

Table 2. Mean degree of conversion (\%) and standard deviation ( \pm ) for the experimental and control groups

\begin{tabular}{lcc}
\hline Groups & Means \pm SD & $\begin{array}{c}\text { p value - } \\
\text { Dunnett’s test }\end{array}$ \\
\hline Control group & $59.5 \pm 3.4$ & - \\
Hemostop & $56.7 \pm 4.9^{\mathrm{B}}$ & 0.382 \\
Viscostat Clear & $57.4 \pm 1.9^{\mathrm{B}}$ & 0.583 \\
Viscostat & $65.5 \pm 1.5^{\mathrm{A}}$ & $0.026^{*}$ \\
\hline
\end{tabular}

Different letters indicate statistically significant difference among the experimental groups, ( $p<0.05$, Tukey's HSD test). ${ }^{*}$ Indicate statistically significant difference between each experimental group compared with control group ( $\mathrm{p}<0.05$, Dunnett's test). after all variance tests $(\mathrm{p}<0.05)$. Also, One-way ANOVA and Dunnett's test were used on $\mu \mathrm{SBS}$ and DC to compare the control group (positive) with experimental groups. The failure modes were evaluated qualitatively followed by the chi-square test, and elemental chemical analysis (EDS) of the fracture surfaces was performed.

\section{Results}

\section{Degree of Conversion (DC)}

The results for the $D C$ are shown in Table 2. Significant differences were verified among the groups $(p=0.002)$, with Viscostat (VS) presenting higher DC values than Hemostop (HS) and Viscostat Clear (VC). No significant differences were observed between $\mathrm{HS}$ and VC with the control group. However VS had significantly higher DC than control group (Table 2).

\section{Color Stability}

Figure 1 show the color readings quantified in terms of the $L^{*}, a^{*}, b^{*}$ coordinate values established by the Commission Internationale de l'Eclairage (CIELAB system). The data for $\triangle \mathrm{E}$ are presented in Table 3 . The aging $(P<0.001)$ and interaction between contamination and aging $(P<0.001)$ influenced color stability. Tukey test demonstrated that $\mathrm{HS}$ and VC had significant lower $\Delta \mathrm{E}$ than VS and $\mathrm{CT}$, and no difference was found between $\Delta \mathrm{E}$ values for $\mathrm{CT}$ and VS at 1 month. On the other hand, at 6 months the VS had significant lower $\Delta \mathrm{E}$ values than $\mathrm{HS}$, and $\mathrm{VC}$ had significant higher $\Delta \mathrm{E}$ values than VS (Table 3). Color stability was found for the CT and VS groups, however, $\Delta \mathrm{E}$ increased with time for the HS and VC groups.

\section{Elemental Chemical Analysis (EDS)}

Table 4 shows the overall results for the EDS performed on the specimens from each group. The elements carbon (C), nitrogen $(\mathrm{N})$, oxygen $(\mathrm{O})$, and silicon $(\mathrm{Si})$ were detected in all groups. For the resin cement specimens contaminated with $\mathrm{HS}$ and VC, the presence of other elements, such as chlorine

Table 3. Mean DE and standard deviation (SD) for the experimental and control groups

\begin{tabular}{lcc}
\hline \multirow{2}{*}{ Groups } & \multicolumn{2}{c}{ Storage periods } \\
\cline { 2 - 3 } & 1 month & 6 months \\
\hline Control group & $2.94 \pm 0.97^{\mathrm{Aa}}$ & $3.34 \pm 1.17^{\mathrm{Ba}}$ \\
Hemostop & $1.90 \pm 0.68^{\mathrm{Bb}}$ & $5.40 \pm 2.35^{\mathrm{Aa}}$ \\
Viscostat Clear & $2.00 \pm 0.55^{\mathrm{Bb}}$ & $10.03 \pm 1.18^{\mathrm{Aa}}$ \\
Viscostat & $3.55 \pm 1.82^{\mathrm{Aa}}$ & $3.51 \pm 2.13^{\mathrm{Ba}}$ \\
\hline
\end{tabular}

Means followed by the same letter (uppercase in columns and lowercase in rows) did not differ by Tukey's multiple-comparison test with 5\% level of significance. 

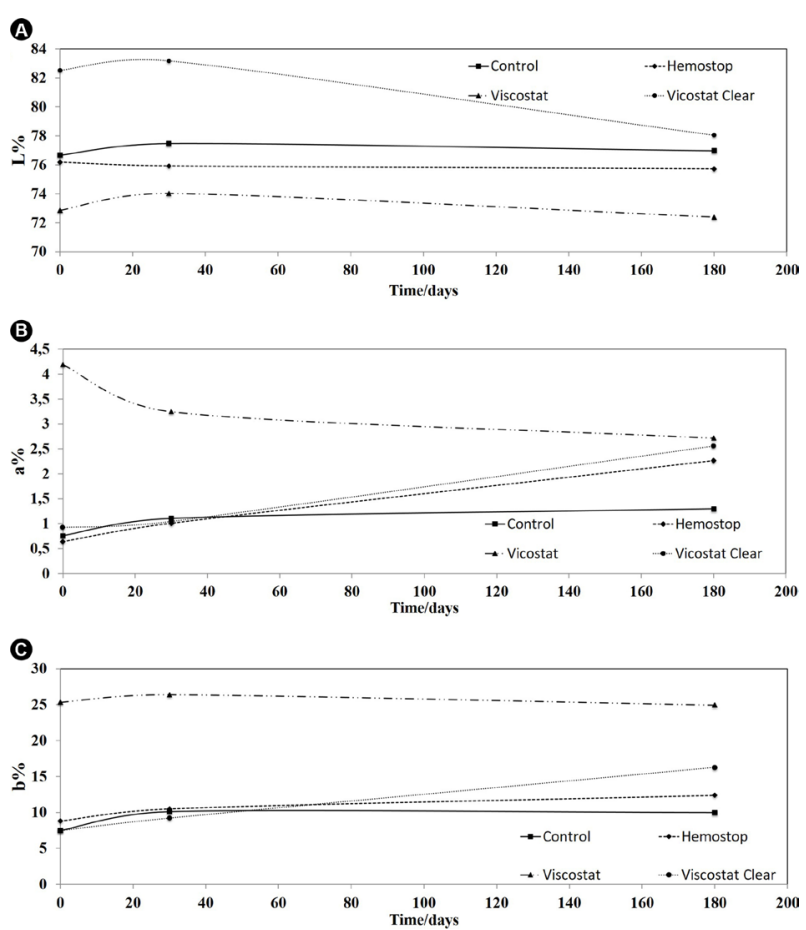

Figure $1 . \mathrm{L}^{*} \Delta \mathrm{L}$ color change of light-cured resin cement contaminated with hemostatic solutions. The $L^{*}$ axis represents the degree of lightness within a specimen and ranges from 0 (black) to 100 (white). $\Delta \mathrm{L}=$ $\vec{\sigma}$ measurement of color change after the aging $\mathrm{a}^{*}$ and $\Delta \mathrm{a}=$ color change \pm of light-cured resin cement contaminated with hemostatic solutions. $a^{*}$ represents the degree of green $/ \mathrm{red} . \Delta \mathrm{a}=$ measurement of color change after aging, and $\mathrm{B}^{*}$ and $\Delta \mathrm{b}$ represent color change of light-cured resin cement contaminated with hemostatic solutions. $b^{*}$ represents the degree of blue/yellow. $\Delta \mathrm{b}=$ measurement of color change after aging.

Table 4. Elemental chemical constitution (\%) of the groups

\begin{tabular}{lcccccccccc}
\hline \multirow{2}{*}{ Groups } & \multicolumn{10}{c}{ Chemical elements (\%) } \\
\cline { 2 - 10 } & $\mathrm{C}$ & $\mathrm{N}$ & $\mathrm{O}$ & $\mathrm{Si}$ & $\mathrm{Al}$ & $\mathrm{Cl}$ & $\mathrm{Ca}$ & $\mathrm{Fe}$ & $\mathrm{S}$ & Total \\
\hline Control & 34.9 & 25.9 & 12.9 & 26.1 & - & - & - & - & - & 100.0 \\
Hemostop & 33.6 & 2.2 & 21.2 & 38.4 & 1.1 & 2.2 & 1.1 & - & - & 100.0 \\
Viscostat Clear & 32.5 & 11.9 & 11.1 & 40.5 & 1.9 & 1.2 & 0.4 & - & - & 100.0 \\
Viscostat & 47.4 & 20.8 & 3.1 & 26.1 & - & - & - & 0.2 & 2.07 & 100.0 \\
\hline
\end{tabular}

C: carbon; N: nitrogen; O: oxygen; Si: silicon; Al: aluminum; Cl: chlorine; Ca: calcium; Fe: iron; S: sulfur.

Table 5. Mean and standard deviations of bond strength (MPa) in the study groups

\begin{tabular}{lccc}
\hline \multirow{2}{*}{ Groups } & \multicolumn{3}{c}{ Storage periods } \\
\cline { 2 - 4 } & $24 \mathrm{~h}$ & 1 month & 6 months \\
\hline Control Group & $24.0 \pm 3.1^{\mathrm{Aa}}$ & $26.1 \pm 3.6^{\mathrm{Aa}}$ & $24.2 \pm 3.6^{\mathrm{Aa}}$ \\
Hemostop & $14.2 \pm 4.1^{\mathrm{Ab}}$ & $13.7 \pm 4.1^{\mathrm{Ab}}$ & $11.1 \pm 3.9^{\mathrm{Ab}}$ \\
Viscostat Clear & $11.2 \pm 2.7^{\mathrm{Ac}}$ & $8.9 \pm 4.6^{\mathrm{Ac}}$ & $9.3 \pm 3.4^{\mathrm{Ac}}$ \\
Viscostat & $13.0 \pm 2.9^{\mathrm{Ab}}$ & $11.2 \pm 3.5^{\mathrm{Ab}}$ & $10.8 \pm 3.1^{\mathrm{Ab}}$ \\
\hline
\end{tabular}

Means followed by the same letter (uppercase in columns and lowercase in rows) did not differ by Tukey's HSD test $(\mathrm{p}<0.05)$.
(Cl), aluminum (Al), and calcium (Ca), was also verified. In the specimens contaminated by VS, the presence of iron (Fe) and sulfur (S) was also detected.

\section{Bond Strength ( $\mu S B S$ )}

The mean and standard deviation values of bond strength for the groups according to storage time are shown in Table 5. Significant effect was verified for the hemostatic agent factor $(p<0.001)$, but no significant effects were observed for the time factor ( $p=0.054$ ) or for the interaction between hemostatic agent and time factors ( $p=0.316)$. Dunnett's test showed that the control group had significantly higher bond strength than HS, VS and VC irrespective of time evaluated, 24h, 1 and 6 months. Comparing the experimental groups, Tukey test showed HS and VS had significant higher bond strength than $\mathrm{VC}$, irrespective of the time evaluated, $24 \mathrm{~h}$, 1 and 6 months.

\section{Failure Mode}

The different types of failures observed in the specimens after the $\mu$ SBS test are illustrated in Figure 2, and the failure mode distribution (\%) for each group is shown in Figure 3. The failure mode was influenced by time $(p=0.021)$ and the type of hemostatic agent $(p<0.001)$. A prevalence of mixed failures in ceramic was observed for the CT group. The HS group exhibited a prevalence of adhesive failures, while the VS and VC groups showed both adhesive and mixed failures in cement.

\section{Discussion}

The null hypothesis of this study was rejected, since the degree of conversion, color stability, and bond strength of the light-cured resin cement tested were influenced by the contamination with hemostatic solutions containing aluminum chloride or ferric sulfate.

In the present study, the DC was measured following $24 \mathrm{~h}$ of specimen preparation, since the polymerization of resin-based materials can increase over time, (19) with higher values being reached after 24h (18). The results showed higher DC values for the VS group as compared with the other groups, which can probably be explained by the lower amount of oxygen observed for this group in the EDS chemical evaluation (Table 4). During polymerization, oxygen reacts rapidly with free radicals, and its presence slows the reaction. This probably did not occur in this group, allowing the polymerization mechanism to be more effective. Conversely, analysis of the EDS data showed a significant increase in the oxygen percentage for the HS group, which presented 
lower DC. Again, this can probably be explained by the same mechanism, in which free radicals can react with oxygen, affecting the polymerization process (20).

Some studies that evaluated the effects of hemostatic agents on dentin bonding strength used direct contamination of the dentin $(13,21)$. In our research, the hemostatic agent was mixed with the resin cement because, in clinical situations, the direct contact of the hemostatic solution can contaminate the resin cement first, rather than the ceramic substrate. This simulates what might happen, especially in the cervical region, where the possibility of contamination of the resin cement by hemostatic agents is real when these products are associated with retraction cords during luting procedures.

Regarding bond strength, it is known that hemostatic solutions can interfere with the bond strength to tooth structures (13). Therefore, the evaluation of the effects of such substances on the bond strength of resin cements to ceramic substrates also becomes important. When ceramic restorations are bonded to dental substrates, it is crucial that optimal adhesion of the resin cement to both the dentin and ceramic surfaces be ensured (22). Our findings showed that the contamination of a resin cement by hemostatic agents reduced bond strength to the ceramic substrate, since the CT group showed better bond strength results (Table 5). These results indicate that the cement contamination with hemostatic solutions affected its chemical performance and decreases its bonding ability.

Additionally, it was suggested that a slight increase in the viscosity of resin-based materials may cause a decrease in their bond strength. In this study, despite the fact that the VS group presented a higher degree of conversion, the VS and VC groups had lower bond strength values, possible due their viscosity, which was not tested in this study, but should be included in future researches. Lower bond strengths may lead to detachment of the restoration on some level, leading to early failures, and consequently reducing the longevity of the restorative procedure. Thus, the integrity of dentin-cement and cement-ceramic interfaces is essential for the survival of adhesive restorations (22).

The distribution of failure modes showed the prevalence of adhesive and mixed failures, with a prevalence of mixed failures in the ceramic for the CT group, probably due to strong bonding at the adhesive interface (23). A prevalence
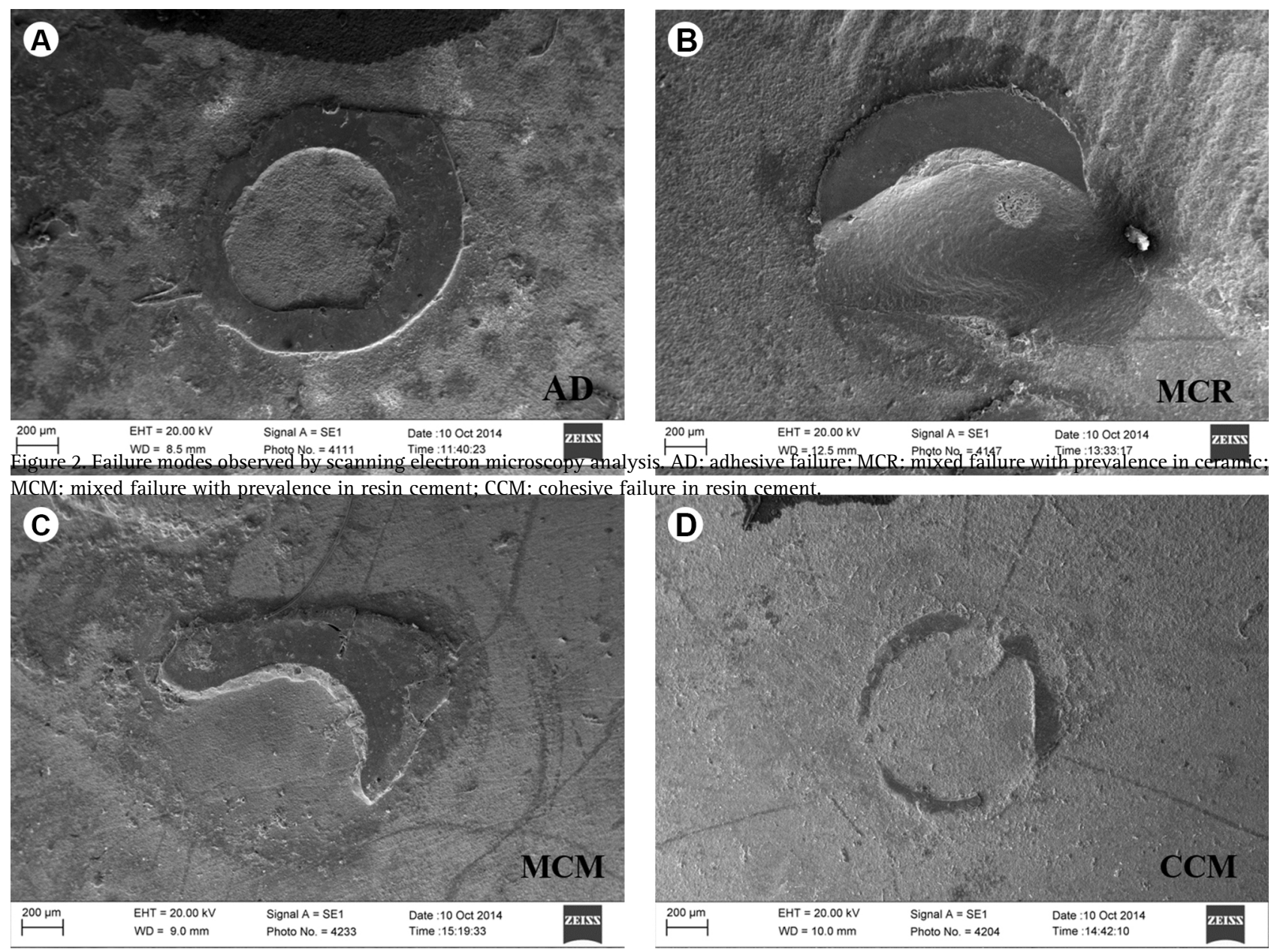
of adhesive failures was verified for the contaminated groups, followed by mixed failure predominantly in cement subjected to increased storage time in artificial saliva. This can be explained by a negative influence of hemostatic agents in the body of the resin cement over time. However, variations in the failure mode can be reflected by several factors, including the storage media, the test used for bond strength analysis, and the different contents of the restorative materials tested. Other laboratory tests and clinical trials are therefore needed to confirm the data obtained in this in vitro study.

The color stability of restorative materials is critical to meet suitable esthetic requirements. The aging process was used to examine the changes in the physical characteristics (color) of the materials tested over time. With respect to $L^{*}$ (Fig. 1), which is responsible for the coordinated brightness between white and black, the VC group had higher values of $L^{*}$ in the immediate analysis (toward white), while the VS group showed lower values (related to darkening of the specimens). These results were expected, since the specimens in the VC group were visibly lighter than the specimens of the other groups, and the VS group was already visibly more yellow, probably due to the presence of the iron element (Fe). The 6-month storage time favored the darkening of specimens of all groups, with a decrease of $L^{*}$. The analysis of coordinated $\mathrm{a}^{*}$ showed that the VS group had higher values of $a^{*}$ (toward red). Nonetheless, after 6 months' storage, the high level of saturation presented by this group was reduced. The $b^{*}$ coordinate analysis showed that the VS group has the darkest color (in the form of yellow), while the other groups have not shown significant differences initially. The storage time produced increased saturation toward yellow for all tested groups. The VC group showed greater instability of brightness and chromaticity (high values of $\Delta \mathrm{L}, \Delta \mathrm{a}$, and $\Delta \mathrm{b}$ ), HS also presented light instability (high values of $\Delta \mathrm{L}$ ), and VS changed by chromaticity (high values of $\Delta$ a). The total variation analysis of all parameters represented by $\Delta \mathrm{E}$ revealed that the $\mathrm{VC}$ group, followed by the HS group, had more color instability after 6 months storage because $\Delta \mathrm{E}$ had higher values. This result can be explained by the higher oxidation potential presented by aluminum, since, in both groups, contamination was created with agents containing aluminum chloride. Aluminum presents a low $\Delta G$ value (Gibbs free energy), which in fact, makes it more susceptible to rust easily (24). Furthermore, these substances contain hydroxyquinoline, which provided oxygen and light quinones, and thus may have caused darkening of the material.

According to Ruyter et al., (25) $\Delta$ E values smaller than 3.3 are considered acceptable for dental composites, while results higher than that are noticeable to the human eye. In this study, after 6 months of storage in artificial saliva, all groups except the Control group, which was considered a borderline case, showed $\Delta$ E values higher than 3.3, which means that the color change would be visible to the human eye. However, there is still controversy in the literature on determination of the visibility of the $\Delta \mathrm{E}$ threshold (25).

Dental restorations are composed of complex color with various degrees of translucency, so color change considered clinically acceptable may also vary in relation to in vitro observations. Since we studied only one type of resin cement, further studies evaluating different cements and different ceramic materials contaminated with hemostatic agents should be conducted. The influence on the color stability of the resin cement should be analyzed carefully because we simulate the worst clinical condition that is the mixing of the hemostatic solution with resin cement. It is difficult to occur into the center of the buccal surface, however it is clearly possible to occur on the cervical margin. The marginal stain is a clinical relevant problem and may be caused by contamination between hemostatic solutions and resin cement during ceramic cementation. If the use of the hemostatic solution is essential to prevent the blood contamination the adequate removal procedure of hemostatic solutions after the cords insertion on the gingival sulcus is fundamental to minimize the contamination preserve the bond strength between resin cement and ceramic restoration and the color stability of the ceramic restoration on the cervical margin.

Within the limitations of this study, the following may me concluded. The contaminating hemostatic agents reduced the bond strength, and altered the color stability of the tested light-cured resin cement. The contamination with $\mathrm{HS}$ and VC did not reduce the $\mathrm{DC}$ of the resin cement,
Figure 3. Frequency distribution of failure modes (\%): AD, adhesive failure; MCR, mixed failure with prevalence in ceramic; MCM, mixed failure with prevalence in resin cement; CCR, cohesive failure in ceramic; CCM, cohesive failure in resin cement. *Statistically significant difference for hemostatic agents $(\mathrm{p}<0.001)$ and time $(\mathrm{p}=0.021)$. 
and the contamination with VS increased the DC compared with control group. The control group presented higher bonding strength compared with that of the experimental groups, and the storage time in artificial saliva for 1 month and 6 months did not influence the results. The color stability of light-cured resin cement was influenced by storage time and interaction between contamination and storage time, with the agents containing aluminum chloride ( $\mathrm{VC}$ and $\mathrm{HS}$ ) presenting higher $\Delta \mathrm{E}$ values after 6 months.

\section{Resumo}

0 objetivo desse estudo foi avaliar o grau de conversão, estabilidade de cor, composição química e resistência de união de um cimento resinoso fotoativado contaminado com três soluções hemostáticas diferentes. Foram preparadas amostras para o grupo controle (cimento não contaminado) e grupos experimentais (cimento contaminado com uma das soluções hemostáticas) de acordo com os testes. Para o grau de conversão e análise de cor $(n=10)$, as amostras ( $3 \mathrm{~mm}$ de diâmetro e $2 \mathrm{~mm}$ de espessura) foram avaliadas por espectroscopia de infravermelho com transformação de Fourier (FIR) e espectrofotometria CIELAB $\left(L^{*}, A^{*}, B^{*}\right)$, respectivamente. Para a análise química elementar $(n=1)$, os espécimes $(2$ $\mathrm{mm}$ de espessura e $6 \mathrm{~mm}$ de diâmetro) foram avaliados por espectroscopia de energia dispersiva de raios- $x$ (EDS). As resistências de união dos grupos foram avaliadas pelo ensaio de microcisalhamento $(n=20)$ em um substrato cerâmico de vidro reforçado com leucita, seguida da análise de modo de falha por microscopia eletrônica de varredura (MEV). Os valores médios, com exceção da avaliação quimica e do modo de falha, foram avaliados por ANOVA e pelo teste de Tukey. A estabilidade de cor foi influenciada pelo tempo de armazenagem $(p<0,001)$ e interação entre a contaminação e o tempo $(p<0,001)$. A contaminação pelo Hemostop e Viscostat Clear não influenciaram no GC, porém a contaminação com Viscostat aumentou o GC. A resistência de união do cimento a cerâmica foi negativamente afetada pelos contaminantes $(p<0,001)$. A contaminação por agentes hemostáticos afetou a resistência de união, o grau de conversão e a estabilidade de cor do cimento resinoso fotoativado testado.

\section{Acknowledgements}

This project was supported by the Minas Gerais Research Foundation (FAPEMIG) and CNPq. The study was developed at CPBio (Biomechanics, Biomaterials and Cell Biology Research Center), the Institute of Chemistry of the Federal University of Uberlândia, and LIPq (Integrated Research Laboratory) at the Institute of Science and Technology of São José dos Campos, São Paulo State University (UNESP).

\section{References}

1. Runnacles $\mathrm{P}$, Correr GM, Baratto Filho $F$, Gonzaga CC, Furuse AY. Degree of conversion of a resin cement light-cured through ceramic veneers of different thicknesses and types. Braz Dent J 2014;25:38-42.

2. Saker $S$, Alnazzawi A, Ozcan M. Adhesive strength of self-adhesive resins to lithium disilicate ceramic and dentin: effect of dentin chelating agents. Odontology 2016;104: 53-59.

3. Bagis B, Turgut S. Optical properties of current ceramics systems for laminate veneers. J Dent 2013;41Suppl3:24-30.

4. Groten M, Probster L. The influence of different cementation modes on the fracture resistance of feldspathic ceramic crowns. Int J Prosthodont 1997:10:169-177.

5. Janda R, Roulet JF, Kaminsky M, Steffin G, Latta M. Color stability of resin matrix restorative materials as a function of the method of light activation. Eur J Oral Sci 2004; 112:280-285.

6. Prasanna N, Pallavi Reddy Y, Kavitha S, Lakshmi Narayanan L. Degree of conversion and residual stress of preheated and room-temperature composites. Indian J Dent Res 2007;18:173-176.
7. O'Brien WJ. Dental materials and their selection. Quintessence Publishing 2008; Chicago, IL, USA

8. Usumez S, Buyukyilmaz T, Karaman Al, Gunduz B. Degree of conversion of two lingual retainer adhesives cured with different light sources. Eur J Orthod 2005;27:173-179.

9. Donovan TE, Chee WW. Current concepts in gingival displacement. Dent Clin North Am 2004;48:433-444.

10. Kilic K, Arslan S, Demetoglu GA, Zararsiz G, Kesim B. Do blood contamination and haemostatic agents affect microtensile bond strength of dual cured resin cement to dentin?. J Appl Oral Sci 2013;21:85-91.

11. Tarighi P, Khoroushi M. A review on common chemical hemostatic agents in restorative dentistry. Dent Res J 2014;11:423-428.

12. Mohan $M$, Gupta $A$, Shenoy $V$, Parolia A Pharmacological agents in dentistry: a review. Br J Pharm Res 2011;1:66-87.

13. Kuphasuk W, Harnirattisai $C$, Senawongse P, Tagami J. Bond strengths of two adhesive systems to dentin contaminated with a hemostatic agent. Oper Dent 2007;32:399-405.

14. Land MF, Couri CC, Johnston WM. Smear layer instability caused by hemostatic agents. J Prosthet Dent 1996;76:477-482.

15. Silva EM, Poskus LT, Guimaraes JG, de Araujo Lima Barcellos A, Fellows CE. Influence of light polymerization modes on degree of conversion and crosslink density of dental composites. J Mater Sci Mater Med 2008;19:1027-1032.

16. Ferracane JL, Greener EH. Fourier transform infrared analysis of degree of polymerization in unfilled resins - methods comparison. J Dent Res 1984;63:1093-1095.

17. Gajewski VE, Pfeifer CS, Froes-Salgado NR, Boaro LC, Braga RR. Monomers used in resin composites: degree of conversion, mechanical properties and water sorption/solubility. Braz Dent J 2012;23:508-514.

18. Borges AB, Zanatta RF, Barros AC, Silva LC, Pucci CR, Torres CR. Effect of hydrogen peroxide concentration on enamel color and microhardness. Oper Dent 2015;40:96-101.

19. Furuse AY, Mondelli J, Watts DC. Network structures of Bis-GMA/ TEGDMA resins differ in DC, shrinkage-strain, hardness and optical properties as a function of reducing agent. Dent Mater 2011;27:497-506.

20. Brauchli $L$, Eichenberger $M$, Steineck $M$, Wichelhaus $A$. Influence of decontamination procedures on shear forces after contamination with blood or saliva. Am J Orthod Dentofacial Orthop 2010;138:435-441.

21. Bernades Kde O, Hilgert LA, Ribeiro AP, Garcia FC, Pereira PN. The influence of hemostatic agents on dentin and enamel surfaces and dental bonding: a systematic review. J Am Dent Assoc 2014;145:11201128.

22. Castro HL, Passos SP, Zogheib LV, Bona AD. Effect of cement shade and light-curing unit on bond strength of a ceramic cemented to dentin. J Adhes Dent 2012;14:155-160.

23. Armstrong $S$, Geraldeli $S$, Maia R, Raposo LH, Soares CJ, Yamagawa J. Adhesion to tooth structure: a critical review of "micro" bond strength test methods. Dent Mater 2010;26:e50-e62.

24. Ellingham HJT. Transactions and communications. J.Soc. Chem. Industry 1944:63:125.

25. Ruyter IE, Nilner K, Moller B. Color stability of dental composite resin materials for crown and bridge veneers. Dent Mater 1987;3:246-251.

Received January 4, 2017 Accepted May 25, 2017 